there can be no doubt that the most important part of the apparatus-the peripheral-remains intact after the division, though more or less permanently crippled in its fúnctions.

But though the greater portion of the memoir is devoted to a discussion of the physiology of the vaso-motor nervous system, under various rclations, some of them in a degree irrelevant, yet after the review of the work of M. Vulpian, which either has been, or is to be made, it will hardly prove useful to enter upon an extended discussion of the contents of this paper.

There is one point, however, that has been made by M. Legros in respect to thythmical action of the muscular vessels as an aid in the circulation of the blood, to the consideration of which we would be glad to devote some time. But inasmuch as this same topic was pretty fully discussed in the July number of the last volume, we do not feel obliged to call it up again, though it merits a more careful discussion than we have been able to give it.

The paper closes with a few suggestive remarks on the application of the principles deduced in the preceding parts of the work to the domain of pathology. But we must pass this clear and interesting paper by, with heartily recommending it to our readers who are in search of information on the subject of which it treats. And here, without finishing our list of works, we must close this notice, for the reason that we can afford no more space to it, though notices of three of the other memoirs had been written-especially on the works of Schiff and Meryon. Some mention unay be made of them in reviewing the second volunie of M. Vulpian.

\title{
II.-HARTLEY, ON MAN.
}

Observations on Mai; his frame, his DUty, and his mixpectatrons. In two parts. Part I., containing observations on the frame of the human body and mind, and on their mutual connexions and influences. Part II., etc., etc., etc. Also a sketch of the life and character, and a head of the author. Quarto, pp. 756. London: 1791.

And why call up the work of Hartley, first published more than a century ago (1749)? Firstly, because it contains useful and interesting matter for consideration, even now, by the celebrated founder of the "Hartleian school"; and secondly, becausc we wish to show by the example of Hartley, how much may be done in the cautious use of inference, against any but the most restricted use of which, there is such a decided feeling in certain quarters to-day. 
ductibility of nerve-fibres-the division of the brain into parts or regions corresponding to the various nerves of the bodyon his truly admirable remarks as to the physiological aspect of the process of obtaining a knowledge of space relations -on the seats of true sensibility and of mental action-on the duality of the nervous system-on muscular tonus-on heredity, and the relations of body and mind; under all of which headsnot to mention others--there are highly interesting remarks that may well be adopted as expressing in the main, the present state of physiological science as touching the same matters, but we are obliged to pass all of them by with a bare recital of points.

But.if we mistake not, we have cited a sufficient number of passages already, to show how much Hartley was in advance of the physiology of his times in respect to the structure and modes of action of the nervous system. By what means did Hartley arrive at so many just views in respect to the difficult subject on which he wrote? Simply by doing what his illustrious master Newton did when he discovered the law of gravitation, by patient reflection, on a fact so simple as the fall of an apple; which fact, common as it was and is, involves really the law, which by generalization was seen to extend its jurisdiction throughout the visible universe. Even so it was with Hartley. Reflecting cautiously and patiently on the few facts that he had accumulated, and aided by an ingenious theory, he was able to declare in fair outline the structure and probable modes of action of important parts of the nervous system, as legitimate deductions from rational premises. If so much could be done by Hartley on the basis of so few ascertained facts, guided by a cantious but free use of inference, what might not be done to-day when such multitudes of facts await, in incoherent masses, the hand of patient critical reflection? We are as well aware as we can be, that we are proclaiming no new truth, nor recommending any new practice, when we declare that the greatest need in the sphere of the natural and physical sciences of to-day is not less experimentation, but more and better balanced thought, or more logical reflective power, and a freer, because a more rational use of inference. And we are ready to justify our remarks when we say, that there is a well-marked loss of balance now existing in the general movement of science, in favor of experimentation, as against critical thought on its methods and results. And in no other department of hunian effort is this state of things mor'c conspicuous, or its results more deplorable, than in that of medicine. 